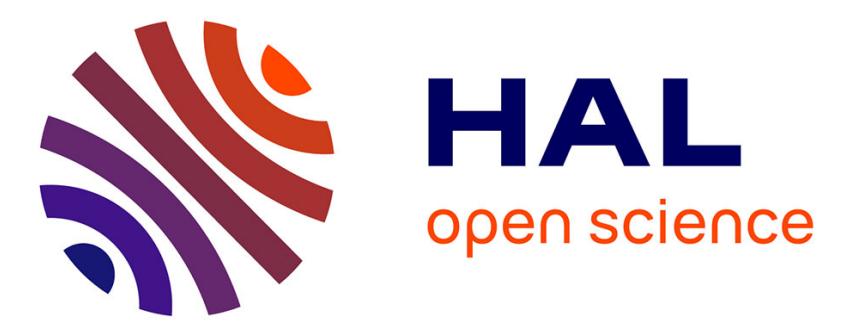

\title{
Ceramic matrix composites manufactured by multistep densification of Si-O-C fibre preform
}

Laurence Maillé, Marie-Anne A Dourges, Simon Le Ber, René Pailler

\section{To cite this version:}

Laurence Maillé, Marie-Anne A Dourges, Simon Le Ber, René Pailler. Ceramic matrix composites manufactured by multistep densification of Si-O-C fibre preform. Ceramic Transactions, 2014, 244, pp.61-69. 10.1002/9781118889770.ch6 . hal-01844825

\section{HAL Id: hal-01844825 \\ https://hal.science/hal-01844825}

Submitted on 19 Jul 2018

HAL is a multi-disciplinary open access archive for the deposit and dissemination of scientific research documents, whether they are published or not. The documents may come from teaching and research institutions in France or abroad, or from public or private research centers.
L'archive ouverte pluridisciplinaire HAL, est destinée au dépôt et à la diffusion de documents scientifiques de niveau recherche, publiés ou non, émanant des établissements d'enseignement et de recherche français ou étrangers, des laboratoires publics ou privés. 


\title{
CERAMIC MATRIX COMPOSITES MANUFACTURED BY MULTISTEP DENSIFICATION OF Si-O-C FIBRE PREFORM
}

\author{
L. Maillé, M.A. Dourges, S. Le Ber, R. Pailler \\ University of Bordeaux, LCTS, UMR 5801, 33600 Pessac, France
}

\begin{abstract}
Ceramic matrix composites have been manufactured at temperatures below $1100^{\circ} \mathrm{C}$ by a multistep process which consists in (i) a polymer impregnation of $\mathrm{Si}-\mathrm{C}-\mathrm{O}$ fibre preform and pyrolysis (PIP) in order to consolidate the preform ; (ii) an impregnation with a slurry of submicronic $\mathrm{TiSi}_{2}$ powder, (iii) a heat treatment under nitrogen $\left(\mathrm{N}_{2}\right)$ in order to reduce the porosity thanks to the volume expansion associated with the nitridation of the active filler; and (iv) a final densification by PIP. Various liquid polymeric precursors were investigated to perform this final densification. The morphology, the chemical composition and the mechanical properties of the composites were characterized. Based on these characterizations, a preceramic polymer precursor was chosen in order to produce a ceramic matrix composite.
\end{abstract}

\section{KEYWORDS}

CMC ; active filler ; slurry impregnation ; flexural strength.

\section{INTRODUCTION}

The processing of Ceramic Matrix Composites (CMC), using impregnation and pyrolysis of preceramic polymer precursor (PIP) offers advantages over others processing routes (chemical vapour infiltration, sol-gel route, reactive melt infiltration or several other techniques $\left.{ }^{[} 1^{-} 5^{\mathrm{l}}\right)$; particularly, PIP is based on relatively simple technologies. In order to be competitive on the civil aeronautics market, low cost CMC processing routes must be developed ${ }^{[6-9]}$. PIP of $\mathrm{SiC}$ fibre preforms could be attractive but due to an inherent shrinkage obtained after pyrolysis of the polymer, larges pores are formed in the composite and multiple cycles of PIP must be performed to increase the densification. Complementary methods of densification such as slurry impregnation with filler can be performed before the PIP to obtain an effective process with a low price / performance ratio. However, the repetition of numerous impregnation and pyrolysis cycles is then necessary to obtain a dense material ${ }^{[10]}$. As it has been suggested by P. Greil in the case of ceramic preparation, this problem could be overcome with the use of active fillers, which react during pyrolysis under reactive atmosphere to form oxides, carbides or nitrides leading to a significant volume expansion that can decrease the matrix porosity ${ }^{[11-20]}$. Among various expansion agents, titanium disilicide powder $\left(\mathrm{TiSi}_{2}\right)$ is identified as an interesting active filler ${ }^{[20-}$ 23]. Under nitrogen atmosphere, the nitridation of sub-micronic $\mathrm{TiSi}_{2}$ powder starts around $1000^{\circ} \mathrm{C}$, and leads to the formation of TiN $\left(\mathrm{d}=5.43 \mathrm{~g} / \mathrm{cm}^{3}\right)$ and $\operatorname{Si}_{3} \mathrm{~N}_{4}\left(\mathrm{~d}=3.19 \mathrm{~g} / \mathrm{cm}^{3}\right)$ with a large volume increase even if the reaction is incomplete.

This study explores the processing of ceramic matrix composites by slurry impregnation of submicronic active filler, subsequent nitridation and liquid polymer impregnation and pyrolysis with liquid polymeric precursors. First, pellets prepared from sub-micronic nitrided $\mathrm{TiSi}_{2}$ powder were impregnated with different precursors and heat treated to explore the behaviour of the polymers. According to the experimental results on monolithic matrices, liquid polymeric precursors were chosen to manufacture the fibre reinforced ceramic matrix composites. Finally, the mechanical behaviour (3-point bending tests) of CMCs is characterized in order to select the best polymer precursor. 


\section{MATERIALS AND EXPERIMENTAL PROCEDURE}

\subsection{Materials}

A high purity micrometer-sized $\mathrm{TiSi}_{2}$ powder (C-54 stable phase, $99.95 \%$ in purity, $\sim 45 \mu \mathrm{m}$, Neyco) was used during this work. This raw powder was milled with a planetary ball mill (Retsch PM200).

Composites were fabricated from 2D fibre preforms ( $2 \mathrm{~mm}$ thickness) made of woven Nicalon fibres (Nippon Carbon Co) covered with a PyC interphase. The fiber preforms are first consolidated by one PIP cycle with a phenyl-containing polysiloxane (resin A) ; after this consolidation step the porosity is around $48 \%$. All the preforms used were purchased in the consolidated state. The four resins used as preceramic polymers for the densification of pellets are presented on table 1.

Table1. Ceramic precursor characteristics

\begin{tabular}{|c|c|c|}
\hline Ceramic precursor & Composition & Viscosity \\
\hline Resin A & $\begin{array}{c}\text { Methylphenylvinylhydrogen } \\
\text { polysiloxane resin }\end{array}$ & $900 \mathrm{mPa} . \mathrm{s}$ \\
\hline Resin B & Alkylsilicone resin + xylène & $\begin{array}{c}6-12 \mathrm{~mm}^{2} / \mathrm{s} \\
50 \% \mathrm{w} \text { xylène }\end{array}$ \\
\hline Resin C & $\begin{array}{c}\text { Methyl silicone resin + methyl } \\
\text { ethyl ketone }\end{array}$ & $\begin{array}{c}\text { powder } \\
50 \% \text { methyl ethyl } \\
\text { ketone }\end{array}$ \\
\hline Resin D & $\begin{array}{c}\text { Polymethoxy methylsiloxane / } \\
\text { methyl silsesquioxane resin }\end{array}$ & $23-30$ mPa.s \\
\hline
\end{tabular}

\subsection{Processing of composites}

Powder milling:

The first step is the milling of $\mathrm{TiSi}_{2}$ commercial powders, which are not fine enough to be impregnated into the fibre preforms. They were milled with a planetary ball mill (Retsch PM200). Tungsten carbide (WC, $\mathrm{d}=15.6 \mathrm{~g} / \mathrm{cm}^{3}$ ) accessories were chosen in order to perform high energy millings: a $50 \mathrm{~mL}$ hermetic jar. $18 \mathrm{~g}$ of raw powder and $305 \mathrm{~g}$ of WC balls $(3 \mathrm{~mm}$ in diameter) were loaded with $15 \mathrm{~mL}$ of isopropanol in the $\mathrm{WC}$ jar. The millings were performed at a jar rotational speed of $960 \mathrm{rpm}$ during 3 hours. In order to limit the temperature raise in the jar, the milling time was split in eighteen 10 minutes effective milling periods interrupted by 20 minutes cooling periods. The milled powder was collected by evaporating the solvent at $100^{\circ} \mathrm{C}$ under vacuum (grain size diameter $\mathrm{d}_{50}: 0.5 \mu \mathrm{m}$; $\mathrm{d}_{90}: 1.1 \mu \mathrm{m}$ ).

Processing of composite pellets:

$\mathrm{TiSi}_{2}$ powder was compression moulded to make pellets. Pellets are nitrited $1 \mathrm{~h}$ with a stream of $\mathrm{N}_{2}$ at a temperature of $1100^{\circ} \mathrm{C}$. They were used to study the behaviour of the preceramic precursor during impregnation and pyrolysis in contact with the solid nitrided $\mathrm{TiSi}_{2}$. The pellets were immersed in the liquid polymeric precursors (alone or in solution) in a beaker. The beaker was placed in a vessel, which was evacuated and heated at $60^{\circ} \mathrm{C}$ in order to reduce the viscosity of the polymer. After one hour of impregnation, the samples were removed from the beaker and put in a furnace. The pellets were heated under argon atmosphere at a ramping rate of $20^{\circ} \mathrm{C} / \mathrm{min}$ 
up to $200^{\circ} \mathrm{C}$, maintained at this temperature for $2 \mathrm{~h}$ for curing; the temperature was then raised to $900^{\circ} \mathrm{C}$ for pyrolysis at a rate of $10^{\circ} \mathrm{C} / \mathrm{min}$, and maintained at this temperature for $1 \mathrm{~h}$.

Processing of fibre- reinforced composites:

Ceramic matrix composites were prepared with 2D Nicalon fibres. These SiC-based fibres are unstable at high temperatures because of the silicon oxycarbide phase they contain, which decomposes beyond $1100{ }^{\circ} \mathrm{C}$; the manufacturing of $\mathrm{CMC}$ is therefore limited to this maximum temperature. Active filler was impregnated in the preform using slurry impregnation method. The active filler powders were mechanically mixed with ethanol in order to obtain slurry. The addition of poly-ethylene imine (PEI) enabled to stabilize the colloidal suspension. A concentration of $15 \% \mathrm{~V}$ of active filler powder could be obtained with an optimum concentration of $2.5 \mathrm{mg}$ of PEI per square meter of powder. The fibre preforms were immersed in a beaker of suspension and the impregnation was performed under vacuum for one hour. The samples were then removed from the suspension, and the solvent was evaporated by heating at $100^{\circ} \mathrm{C}$ under vacuum for one hour. The composites impregnated with the active filler were then nitrided under a flow of nitrogen gas at a ramping rate of $10^{\circ} \mathrm{C} / \mathrm{min}$ up to $1100^{\circ} \mathrm{C}$, and maintained at this temperature for $5 \mathrm{~h}$. The next step was the PIP cycle with the preceramic polymers presented table 1. The PIP cycles were carried out with the same experimental set-up as for the pellets preparation.

\subsection{Characterizations methods}

The pore size distribution and porosity of the materials were determined by mercury porosimetry (Micromeritics Autopore IV 9500). The microstructure of CMC was observed by scanning electron microscopy (SEM). Experiments were carried out using a Quanta 400 FEG microscope. 3 -points bending strength of test pieces $50 \mathrm{~mm}$ (length) x $10 \mathrm{~mm}$ (width) x $2 \mathrm{~mm}$ (thickness) in size was measured with a universal testing machine (Instron 5860) at a cross-head speed of 0.5 $\mathrm{mm} / \mathrm{min}$ with a span of $30 \mathrm{~mm}$, at room temperature. Two specimens were performed for each experimental condition.

The ultimate flexural strength $\left(\sigma_{\mathrm{R}}\right)$ was calculated according to the equation (1):

$$
\sigma_{\mathrm{R}}=3 \mathrm{~F} \mathrm{~L} / 2 \mathrm{w} \mathrm{t}^{2}
$$

where $\mathrm{F}$ is the maximal applied load, $\mathrm{L}$ the support span $(50 \mathrm{~mm}), \mathrm{w}$ the width $(\sim 10 \mathrm{~mm})$ and $\mathrm{t}$ the thickness $(\sim 2 \mathrm{~mm})$ of the specimen.

\section{RESULTS AND DISCUSSION}

\subsection{PIP of precursors in pellets}

In order to select the preceramic polymers, composite pellets of ceramic were prepared using nitrided $\mathrm{TiSi}_{2}$ cylinders and PIP precursors listed on table 1 . The study of the behavior of resins $\mathrm{A}$ to $\mathrm{D}$ is presented in this paper. As it is shown in table 2, the impregnations were performed in solutions of $50 \mathrm{wt} \%$ of xylene in the case of resin B, of $70 \mathrm{wt} \%$ of methyl ethyl ketone (MEK) in the case the resin $\mathrm{C}$ and without solvent for the resin $\mathrm{A}$ and the resin D. Table 2 presents the composition and porosity obtained for the four composites after one PIP cycle. The ceramic proportion is higher for the materials prepared with the precursors used without solvent. Such result could be expected if we take into account the conditions of impregnation. A large amount of solvent is added to obtain a suitable viscosity for resins B and C. Even if the yield of transformation is high, particularly in the case of resin $\mathrm{C}$, the final proportion of polymer residue in the pellet is low, due to the elimination of the solvent. The best results were obtained with 
resin A and the resin D. Mercury intrusion porosimetry was used to investigate the microstructure of materials.

Table 2. Results of impregnation and pyrolysis of ceramic precursor on pellets of $\mathrm{TiSi}_{2}$ powder

\begin{tabular}{|c|c|c|c|c|c|c|c|}
\hline Samples & Precursor & Solvent & $\begin{array}{l}\text { precursor } \\
\text { proportion }\end{array}$ & $\begin{array}{c}\text { Impregnation } \\
\text { weight gain }\end{array}$ & $\begin{array}{c}\text { Ceramic } \\
\text { yield } \\
\left(900^{\circ} \mathrm{C} / \mathrm{Ar}\right)\end{array}$ & $\begin{array}{c}\text { Proportion } \\
\text { of polymer } \\
\text { residue } \\
\text { (weight })\end{array}$ & Porosity \\
\hline Pellet A & Resin A & - & $100 \%$ & $27 \%$ & $73 \%$ & $21 \%$ & $8.5 \%$ \\
\hline Pellet B & Resin B & $\begin{array}{c}\text { xylène } \\
50 \mathrm{wt} \%\end{array}$ & $50 \%$ & $22 \%$ & $65 \%$ & $15.5 \%$ & $20 \%$ \\
\hline Pellet C & Resin C & $\begin{array}{c}\text { MEK } \\
70 \mathrm{wt} \%\end{array}$ & $30 \%$ & $16 \%$ & $87 \%$ & $14.3 \%$ & $28 \%$ \\
\hline Pellet D & Resin D & - & $100 \%$ & $35 \%$ & $65 \%$ & $26 \%$ & $8 \%$ \\
\hline
\end{tabular}

The pellets $\mathrm{A}$ and $\mathrm{B}$ fabricated with resin A and the resin D offer a lower porosity (about 8\%) than the others obtained from resin B and C (20 and 28\% respectively).

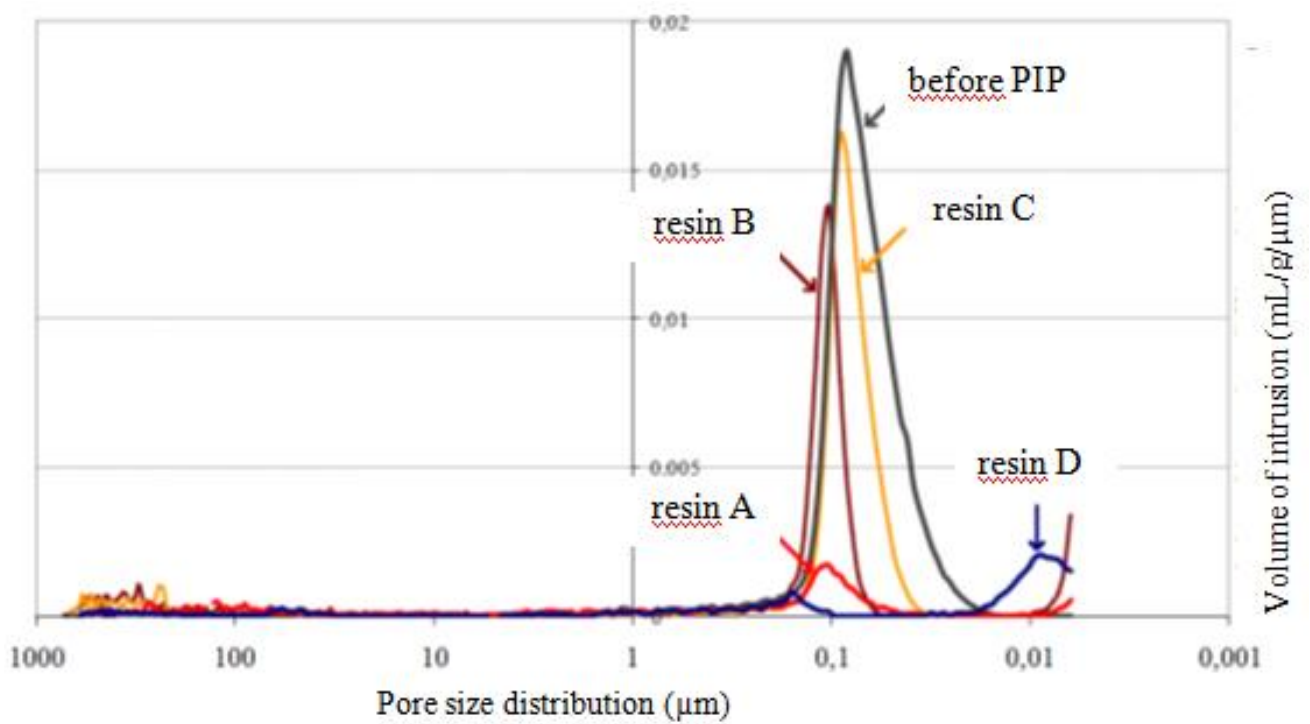

Figure 1. Pore size distribution of the pellet before and after PIP with different preceramic

polymers

Figure 1 shows the pore size distribution of the pellets, after one PIP cycle, for the four materials prepared. The size of the pores is lower than $1 \mu \mathrm{m}$. Table 2 indicates a similar total pore volume of about $8 \%$ for pellets $\mathrm{A}$ and $\mathrm{D}$. But in figure 1, we can observe that the size range of the pores is different, around $100 \mathrm{~nm}$ for the pellet $\mathrm{A}$ and around $10 \mathrm{~nm}$ for pellet D. Difference of initial viscosity of the two precursors can explain this observation. Based on these results, resins A and $\mathrm{D}$ were selected to prepare fibre-reinforced ceramic matrix composites.

3.2. Preparation and characterization of Ceramic Matrix Composites

3.2.1. Composites processing

Three types of composites were produced using the following steps: infiltration of the milled $\mathrm{TiSi}_{2}$ powder $(18 \pm 4 \% \mathrm{w})$, nitridation and one PIP cycle with the resin $\mathrm{A}$ and $\mathrm{D}$. The 
composition of the composite is given in detail in table 3. Proportion of pre-ceramic residue is higher in $\mathrm{CMC} 2$, as observed in the pellets.

Table 3. Fibre-reinforced composites compositions

\begin{tabular}{|c|c|c|c|c|c|}
\hline Sample & Powder & $\begin{array}{c}\text { Thermal } \\
\text { treatment }\end{array}$ & $\begin{array}{c}\text { Polymer used } \\
\text { for the final } \\
\text { PIP }\end{array}$ & $\begin{array}{c}\text { Fraction of } \\
\text { nitrided powder } \\
\text { (Weight \%) }\end{array}$ & $\begin{array}{c}\text { Fraction of } \\
\text { ceramic residue } \\
\text { (Weight \%) }\end{array}$ \\
\hline $\mathrm{CMC} 1$ & $\mathrm{TiSi}_{2}$ & $5 \mathrm{~h}, 1100^{\circ} \mathrm{C}, \mathrm{N}_{2}$ & $\begin{array}{c}\text { Resin A } \\
\text { PIP cycle }\end{array}$ & 20 & 18 \\
\hline $\mathrm{CMC} 2$ & $\mathrm{TiSi}_{2}$ & $5 \mathrm{~h}, 1100^{\circ} \mathrm{C}, \mathrm{N}_{2}$ & $\begin{array}{c}\text { Resin D } \\
\text { PIP cycle }\end{array}$ & 16 & 17.3 \\
\hline $\mathrm{CMC} 3$ & $\mathrm{TiSi}_{2}$ & $5 \mathrm{~h}, 1100^{\circ} \mathrm{C}, \mathrm{N}_{2}$ & $\begin{array}{c}\text { Resin D } \\
\text { 3 PIP cycles }\end{array}$ & 14 & 26 \\
\hline
\end{tabular}

\subsubsection{Characterizations of composites}

The composites were characterized by mercury intrusion porosimetry. The mechanical properties were also determined using 3-point bending tests. The influence of (i) the PIP precursor and (ii) the repetition of the impregnation and pyrolysis cycles were studied. Table 4 summarizes the results. Figure 2 exhibits typical load-displacement curves for all composites. The very first (slightly) non-linear part of the stress-displacement curves may be related to the progressive adjustment of the samples. The first linear part of the curve shows an elastic behaviour of the material; it is followed by a cracking stage until the sample fails. The strengths are distributed between 114 and $163 \mathrm{MPa}$ with only one PIP cycle of resin A and resin D respectively; and reach $215 \mathrm{MPa}$ with three PIP cycles using the resin D. As it was expected, the values of strengths depend particularly on the number of PIP cycles performed. This point can be confirmed regarding the final porosity of CMC measured as $15.5 \%$ for $\mathrm{CMC} 2$ and $7.3 \%$ for CMC3. These results are interesting because the same range of flexural strength values is reported in literature for CMCs elaborated by liquid routes, but in some cases authors choose to multiply PIP cycles $(>6)^{[25-29]}$, even if they introduce passive or active fillers ${ }^{[30-31]}$.

Table 4. Flexural strengths of the CMCs prepared under various conditions (average of 2 specimens).

\begin{tabular}{|c|c|c|c|}
\hline Sample & Polymer & Porosity $(\%)$ & $\begin{array}{c}\text { Flexural } \\
\text { strength } \\
(\mathrm{MPa})\end{array}$ \\
\hline CMC1 & $\begin{array}{c}\text { Resin A } \\
\text { PIP cycle }\end{array}$ & 14.0 & $114( \pm 20)$ \\
\hline CMC2 & $\begin{array}{c}\text { Resin D } \\
\text { PIP cycle }\end{array}$ & 15.5 & $163( \pm 20)$ \\
\hline CMC3 & $\begin{array}{c}\text { Resin D } \\
\text { PIP cycles }\end{array}$ & 7.3 & $215( \pm 25)$ \\
\hline
\end{tabular}




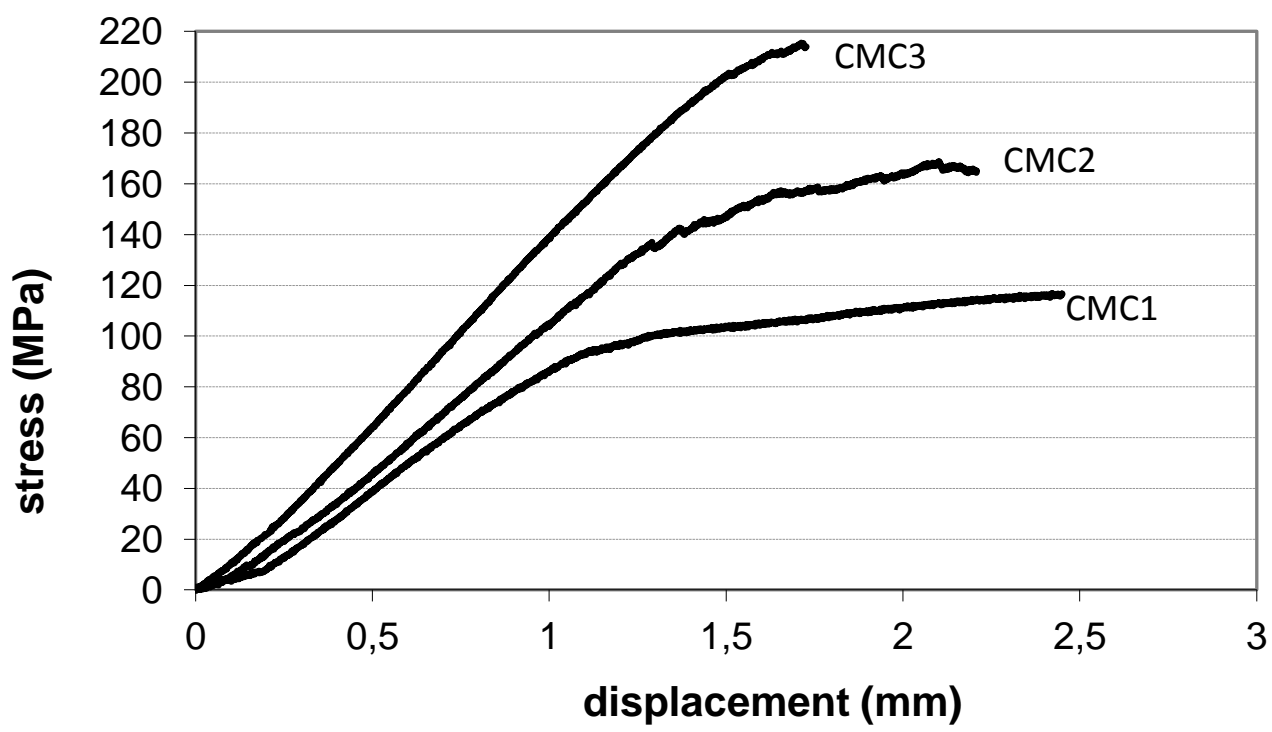

Figure 2. Stress-displacement curves during a 3-point bending test on CMC1, CMC2 and CMC3.

We can notice that using resin D to perform the PIP improves significantly the flexural properties compared to the use of resin A, although the porosity range is the same. To understand this result, microstructure was explored and particularly the repartition of the ceramic residue within the intra-bundle and inter-bundle parts of the composites.

\subsubsection{Microstructure of composites}

Figure 3 presents $\mathrm{CMC1}$ composite micrographs. This observation shows that the powder is impregnated into the inter-bundle macropores. The $\mathrm{TiSi}_{2}$ nitridation created $\mathrm{TiN}, \mathrm{Si}_{3} \mathrm{~N}_{4}$ and free $\mathrm{Si}$ phases ${ }^{[23]}$. Preforms used were consolidated with the resin A, therefore it is not always possible to determine if the observed ceramic residue is the results of the consolidation by the final PIP cycle. However, the following remarks can be made: grain wetting with the resin A appears poor and the ceramic residue does not adhere to grains. Figure 4 presents a SEM micrograph of CMC2, prepared with one PIP cycle using resin D.

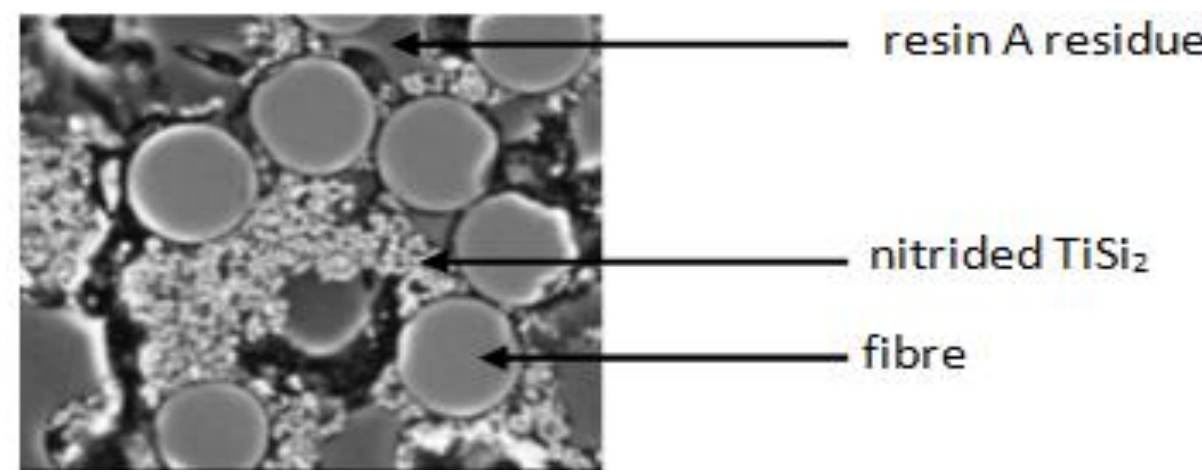

Figure 3. SEM micrograph of polished cross section of a composite (Nicalon preform) elaborated with one impregnation of $\mathrm{TiSi}_{2}$ powder, nitriding $5 \mathrm{~h}$ at $1100^{\circ} \mathrm{C}$ and with one PIP cycle using resin A.

Figure 3 and 4 allow us to appreciate the differences between the behaviour of resins A and D during thermal treatment. Indeed, the resin shrinkage due to the pyrolysis of resin A produces a dense ceramic residue without cracks ; the ceramic residue is not much adherent to fibres and to nitrided powder (figure 3). On the contrary, the pyrolysis of resin D produced a residue which 
exhibits better adhesion to the nitrided powder and fibre as it was revealed by the cracks observed.

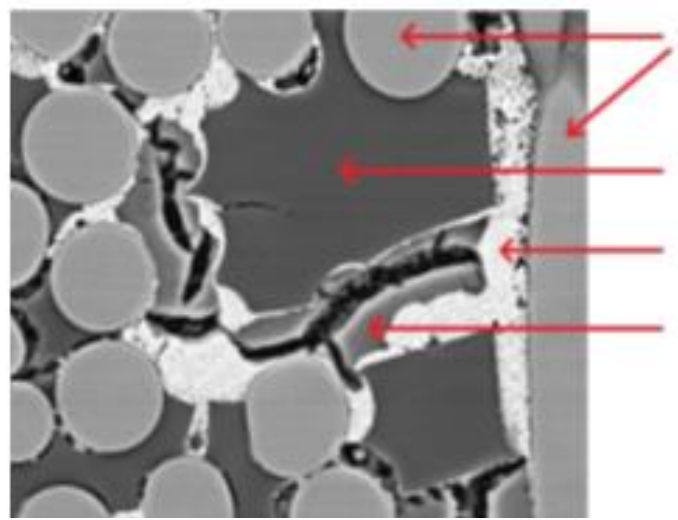

fibres

Resin A residue of the consolidation

nitrided $\mathrm{TiSi}_{2}$

Resin D residue

Figure 4. SEM micrograph of polished cross section of a composite (2D Nicalon preform) elaborated with one impregnation of $\mathrm{TiSi}_{2}$ powder, nitrided $5 \mathrm{~h}$ at $1100^{\circ} \mathrm{C}$ and with one PIP cycle using (CMC2).

Figure 5 shows the distribution of the different constituents inside the composite CMC3. Consolidation residue is particularly localised within the bundle. The nitrided powder fills the inter-bundle macropores. This powder is consolidated by the PIP cycles. Some cracks due to polymer shrinkage can also be observed. This SEM micrograph confirms the low porosity of the composite.

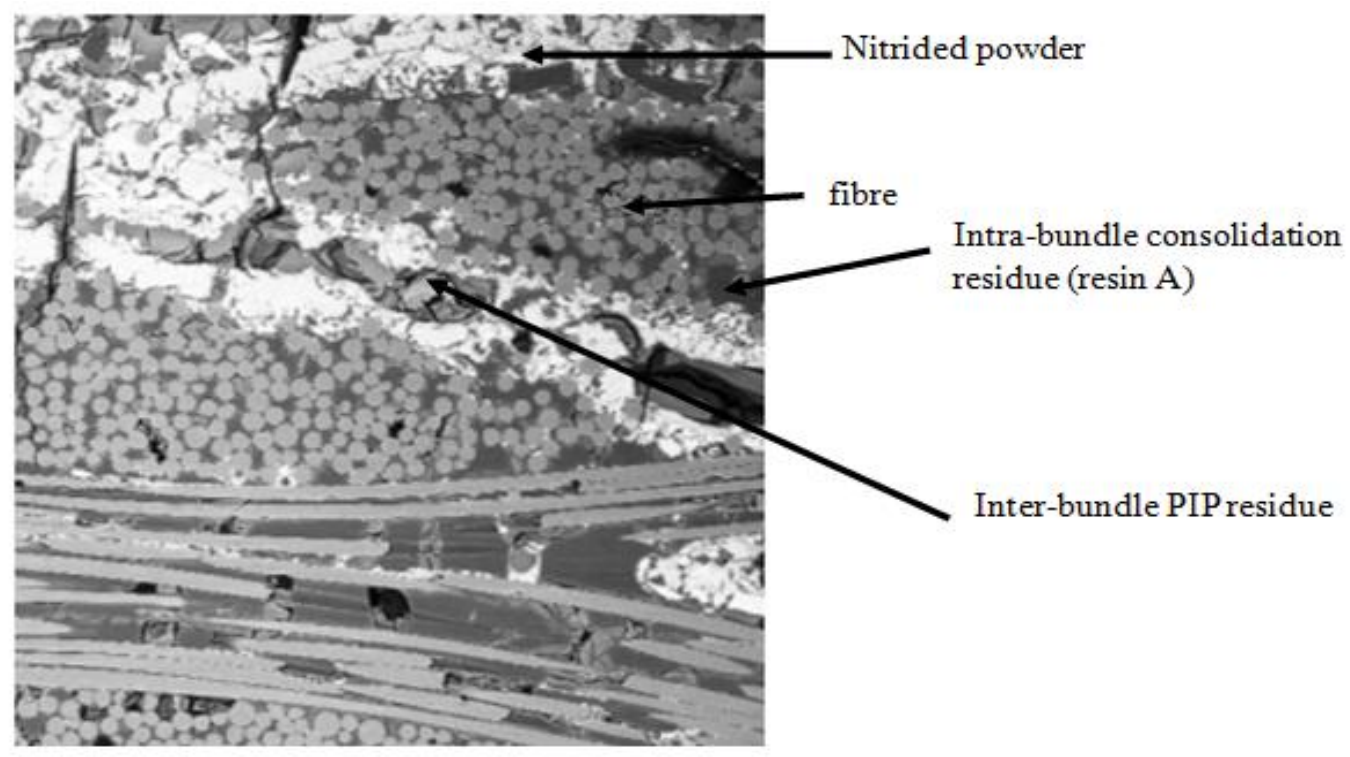

Figure 5. SEM micrograph of cross section of CMC3.

\section{CONCLUSION}

CMC were produced by a relatively simple process combining three different methods of densification. Using impregnation of sub-micronic active filler and nitridation with a volume expansion, part of the porosity was filled. The subsequent PIP cycles with a suitable pre-ceramic polymer allowed to produce a composite with mechanical properties in the same range than 
others CMCs obtained by more complex or more time-consuming processes. Choosing this liquid route and Nicalon fibre preforms enabled to develop a low-cost process performed at temperatures below $1100^{\circ} \mathrm{C}$.

After a study of various ceramic precursors, a resin was selected. This pre-ceramic polymer displayed the best properties to elaborate these composites: a low viscosity at ambient temperature and a good wetting of the nitrided $\mathrm{TiSi}_{2}$ powder. The flexural properties should be improved significantly if the number of PIP cycles was increased.

\section{ACKNOWLEDGEMENTS}

This work was supported by Herakles (Safran Group) and by the French national project NaCoMat.

\section{REFERENCES}

1. R. Naslain, Design, preparation and properties of non-oxide CMCs for application in engines and nuclear reactors: An overview, Compos. Sci. Technol., 64, 155-70 (2004).

2. R. Naslain, SiC-matrix composites: Nonbrittle ceramics for thermo-structural application, Int. J. Appl. Ceram. Technol., 2 (2), 75-84 (2005).

3. M. Rosso, Ceramic and metal matrix composites: routes and properties, J. Mater. Process. Technol., 175 (1-3), 364-75 (2006).

4. J. Magnant, Carbon fiber/reaction-bonded carbide matrix for composite materials Manufacture and characterization, L. Maillé, R. Pailler, J.C. Ichard, A. Guette, F. Rebillat, E. Philippe, J. Europ. Ceram. Soc., 32 (16), 4497-05, 2012.

5. J. Magnant, Fiber-reinforced ceramic matrix composites processed by a hybrid technique based on chemical vapor infiltration, slurry impregnation and spark plasma sintering, R. Pailler, Y. Le Petitcorps, L. Maillé, A. Guette, J. Marthe, E. Philippe, J. Europ. Ceram. Soc., 33 (1) 181-90 (2013).

6. R. Gadow, F. Kern, H. Ulutas, Mechanical properties of ceramic matrix composites with siloxane matrix and liquid phase coated carbon fiber reinforcement, J. Europ. Ceram. Soc., 25, 221-25 (2005).

7. D. Suttor, T. Erny, P. Greil, Fiber-reinforced ceramic-matrix composites with a polysiloxane/boron-derived matrix, J. Am. Ceram. Soc., 80 (7), 1831-40 (1997).

8. S. Azim, C. Solaiyan, G. Venkatachari, Development of coating for temperature sensing, Progress in Organic Coatings, 62 (1), 28-31(2008).

9. M. Woiton, M. Heyder, A. Laskowsky, E. Stern, M. Scheffler, C. J. Brabec, Self-assembled microstructured polymeric and ceramic surfaces, J. Europ. Ceram. Soc., 31 (9) 1803-10 (2011).

10. R. Jones, A. Szweda, D. Petrak, Polymer derived ceramic matrix composites, Composites: Part A, 30 (4), 569-75 (1999).

11. P. Greil, Active-filler-controlled pyrolysis of preceramic polymers, J. Am. Ceram. Soc., 78 (4), 835-48 (1995).

12. P. Greil, Near Net Shape Manufacturing of Polymer Derived Ceramics, J. Eur. Ceram. Soc., 18 (13), 1905-14 (1998).

13. P. Greil, Near net shape manufacturing of ceramics, Mat. Chem. Phys., 61 (1), 64-68 (1999).

14. P. Greil, Pyrolysis of Active and Passive Filler-loaded Preceramic Polymers, Handbook of Advanced Ceramics, ed: S. Somiya, Elsevier Pub. 369-90 (2003). 
15. T. Erny, M. Seibold, O. Jarchow, P. Greil, Microstructure development of oxycarbide composites during active-filler-controlled polymer pyrolysis, J. Am. Ceram. Soc., 76 (1), 207-13 (1993).

16. H.D. Akkas, M.L. Oveçoglu, M. Tanoglu, Silicon oxycarbide-based composites produced from pyrolysis of polysiloxanes with active Ti filler, J. Eur. Ceram. Soc., 26 (15), 3441-49 (2006)

17. Z. Xie, S. Wang, Z. Chen, Active filler (aluminum-aluminum nitride) controlled polycarbosilane pyrolysis, J. Inorg. Organomet. Pol. Mat., 16 (1), 69-81 (2006).

18. M. Ade, J. Hausselt, Electroconductive ceramic composites with low-to-zero shrinkage during sintering, J. Eur. Ceram. Soc., 23 (11), 1979-86 (2003).

19. J.D. Torrey, R.K. Bordia, C.H. Henager, Y. Blum, Y.Shin, W.D. Samuels, Composite polymer derived ceramic system for oxidizing environments, J. Mater. Sci., 41, 4617-22 (2006).

20. D. Vojtech, B. Bartova, T. Kubatik, High temperature oxidation of titanium-silicon alloys, Mater. Sci. Engin., A361, $50-57$ (2003).

21. S. Le Ber, L. Maillé, F. Rebillat, M.-A. Dourges, P. Weisbecker, C. Picard, R. Pailler, HTCMC7 Proceedings, edited by W. Krenkel and J. Lamon, 126-31 (2010).

22. S. Le Ber, M.-A. Dourges, L. Maillé, R. Pailler, A. Guette, Ceramic matrix composites densification by active filler impregnation followed by a P.I.P. process, Ceram. Trans., 215, 113-23 (2010).

23. L. Maillé, M.-A. Dourges, S. Le Ber, P. Weisbecker, F. Teyssandier, Y. Le Petitcorps, R. Pailler, Study of the nitridation process of TiSi2 powder, Applied Surf. Sci., 260, 29-31, 2012.

24. J. Rodriguez-Carvajal, Recent advances in magnetic structure determination by neutron powder diffraction, Physica B Condensed Matter, 192 (1-2), 55-69 (1993).

25. G. Ziegler, I. Richter, D. Suttor, Fiber-reinforced composites with polymer-derived matrix: processing, matrix formation and properties, Composites: Part A, 30 (4), 411-17 (1999).

26. S.M. Dong, Y. Katoh, A. Kohyama, S.T. Schwab, L.L. Snead, Microstructural evolution and mechanical performances of $\mathrm{SiC} / \mathrm{SiC}$ composites by polymer impregnation/microwave pyrolysis (PIMP) process, Ceram. Int., 28 (8), 899-05 (2002).

27. J.M. Cordoba, M.D. Alcala, M.J. Sayagues, M.A. Aviles, C. Real, F.J. Gotor, Nitriding study of titanium silicide intermetallics obtained by mechanical alloying, Intermetallics, 16 (8), 948-54 (2008).

28. C.-C. Lu, M.H. Headinger, A.P. Majidi, T.-W. Chou, Fabrication of a NicalonTM fiber/Si3N4-based ceramic-matrix composite by the polymer pyrolysis method, J. Mat. Sci., 35, 6301-08 (2000).

29. D.-W. Shin, H. Tanaka, Low-temperature processing of ceramic woven fabric/ceramic matrix composites, J. Am. Ceram. Soc., 77 (1), 97-104 (1994).

30. K. Nakano, A. Kamiya, Y. Nishino, T. Imura, T.-W. Chou, Fabrication and characterization of three-dimensional carbon fiber reinforced silicon carbide and silicon nitride composites, J. Am. Ceram. Soc., 78 (10), 2811-14 (1995).

31. G. Stantschev, M. Frieß, R. Kochendörfer, W. Krenkel, Long fibre reinforced ceramics with active fillers and a modified intra-matrix bond based on the LPI process, J. Eur. Ceram. Soc., 25 (2-3), 205-209 (2005). 